\title{
Paraneoplastic chronic intestinal pseudoobstruction as a rare complication of bronchial carcinoid
}

\author{
A Gerl, M Storck, A Schalhorn, J Müller-Höcker, K WJauch, F W Schildberg, W Wilmanns
}

\begin{abstract}
This report describes paraneoplastic visceral neuropathy including achalasia, gastroparesis, subileus and constipation in a 59 year old patient with metastasising atypical bronchial carcinoid. Achalasia was successfully treated by cardiomyotomy and fundoplication; additionally, extramucosal pylorectomy was undertaken to improve gastric emptying. Endoscopic papillotomy was necessary because of a functional stenosis of the sphincter of Oddi with development of obstructive jaundice. Symptoms of intestinal pseudoobstruction did not improve with cisapride or corticosteroid treatment. Histological examination of gastrointestinal specimens revealed a lymphocytic infiltration of the myenteric plexus associated with loss of neurones. The rheumatoid factor was positive, there was evidence of circulating immune complexes and antibodies to $\mathrm{Sm}$ antigen were present, suggesting a possible autoimmune pathogenesis.
\end{abstract}

Chronic intestinal pseudoobstruction is defined as a syndrome of gastrointestinal obstruction in the absence of mechanical blockage and may be caused by various disorders of the smooth muscle and myenteric plexus of the gastrointestinal tract.' Chronic intestinal pseudoobstruction has recently been recognised as a paraneoplastic syndrome in patients with small cell carcinoma of the lung or bronchial carcinoid. ${ }^{23}$ We observed a further case of this rare disorder with findings indicating an autoimmune pathogenesis.

Department of Medicine III,

A Gerl

A Schalhorn

W Wilmanns

Department of Surgery, M Storck

K W Jauch

F W Schildberg

Institute of Pathology, LM University Munich, Klinikum Grosshadern, Munich, West Germany J Müller-Höcker

Correspondence to:

Dr Arthur Gerl, Medizinische Klinik III, LudwigMaximilians-Universität, Klinikum Grosshadern, Marchioninistrasse 15, W-8000 Muenchen 70 , Federal Republic of Germany. Accepted for publication 7 October 1991 recurrence of the bronchial carcinoid. In April 1988 , left supraclavicular lymph node metastases were resected.

In October 1988, the patient presented with abdominal cramps, nausea and vomiting. Upper gastrointestinal tract endoscopy revealed oesophagitis grade III-IV, but no abnormalities in the stomach or duodenum. Colonoscopy detected no mechanical obstruction. Small bowel contrast radiographic examination revealed a moderate dilatation of the entire small bowel and a delayed barium transit in the distal jejunum and ileum without mechanical blockage. At exploratory laparotomy no macroscopic abnormalities of the stomach, small intestine or colon were identified. The oesophagitis improved with metoclopramide and ranitidine but the diffuse abdominal pain, nausea, and vomiting persisted. The patient developed dysphagia and severe obstipation with $13 \mathrm{~kg}$ weight loss within three months.

In December 1988, the patient was readmitted to our hospital. She reported abdominal discomfort and vaginal spasms. On physical examination, inequality of the pupils was striking. The smaller left pupil showed normal constriction to light, but no dilatation to $4 \%$ cocaine. In contrast, the right pupil had an impaired reaction to light, but responded to $4 \%$ cocaine with mydriasis. The abdomen was tender. Digital palpation showed an increased anal sphincter tone. Deep tendon reflexes were symmetrically absent and the patient complained about burning sensations on the palm of her left hand, but electromyography did not provide evidence of a peripheral neuropathy.

Analysis of laboratory data yielded normal results for haematocrit, white blood cell count, platelets, erythrocyte sedimentation rate, creatinine, total bilirubin, alkaline phosphatase, serum glutamic pyruvic transaminase, lactate dehydrogenase and serum protein. Mild leucopenia repeatedly developed with a nadir of white blood cells of $2 \cdot 4 \mathrm{G} / \mathrm{l}$. The gamma globulin fraction in serum electrophoresis was raised to $25 \cdot 4 \%$ (normal range $9 \cdot 8 \%-17 \cdot 5 \%$ ). Further examinations included positive qualitative rheumatoid factor testing, antinuclear antibodies in indirect immunofluorescent test positive with granular pattern (titre 1: 7680), antibodies against RNP (U1 ribonucleoprotein) being negative, Sm-antigen positive, SS-Bantigen ( $\mathrm{La}-\mathrm{ab}$ ) negative, SS-A-antigen ( $\mathrm{Ro}-\mathrm{ab}$ ) negative, antibodies against DNA negative; antimitochondrial antibodies and antibodies against smooth muscle cells were negative. Complement factors $\mathrm{C} 3$ and $\mathrm{C} 4$ were within a normal range. Circulating immune complexes were raised $(17 \%$ binding in Cla binding test, normal 0-9\%). Neurone specific enolase was slightly raised at $17.4 \times 10^{-6} \mathrm{~g} / 1$ (normal range $12.5 \times 10^{-6} \mathrm{~g} / \mathrm{l}$ ). Serum serotonine and urinary hydroxyindole acetic acid were both within a normal range.

Chest radiograph showed that the mediastinum had moved to the right, the left lung was normal. An abdominal computed tomography scan revealed two hypodense areas of $3 \mathrm{~cm}$ in diameter in the liver. A suspicious bone lesion in the right occipital region was detected by a 
cranium roentgenogram. These manifestations were considered to be distant metastases of the bronchial carcinoid.

The following examinations were carried out to analyse gastrointestinal motor dysfunction. Contrast radiograph examination with barium showed a functional high grade obstruction in the distal oesophageal region, which was further investigated by manometry. The lower oesophageal sphincter had a pressure of $15 \mathrm{~mm} \mathrm{Hg}$, with incomplete relaxation. The motor dysfunction was consistent with achalasia (Fig 1). An examination with technetium $99 \mathrm{~m}$-labelled water showed a considerable delay of transit in the middle of the oesophagus. A test with a radioactive labelled solid meal was not tolerated by the patient and a repeated gastroscopic examination could not detect mechanical obstruction, but the pylorus seemed rather rigid. Gastrografin enema disclosed a marked elongation and distension of

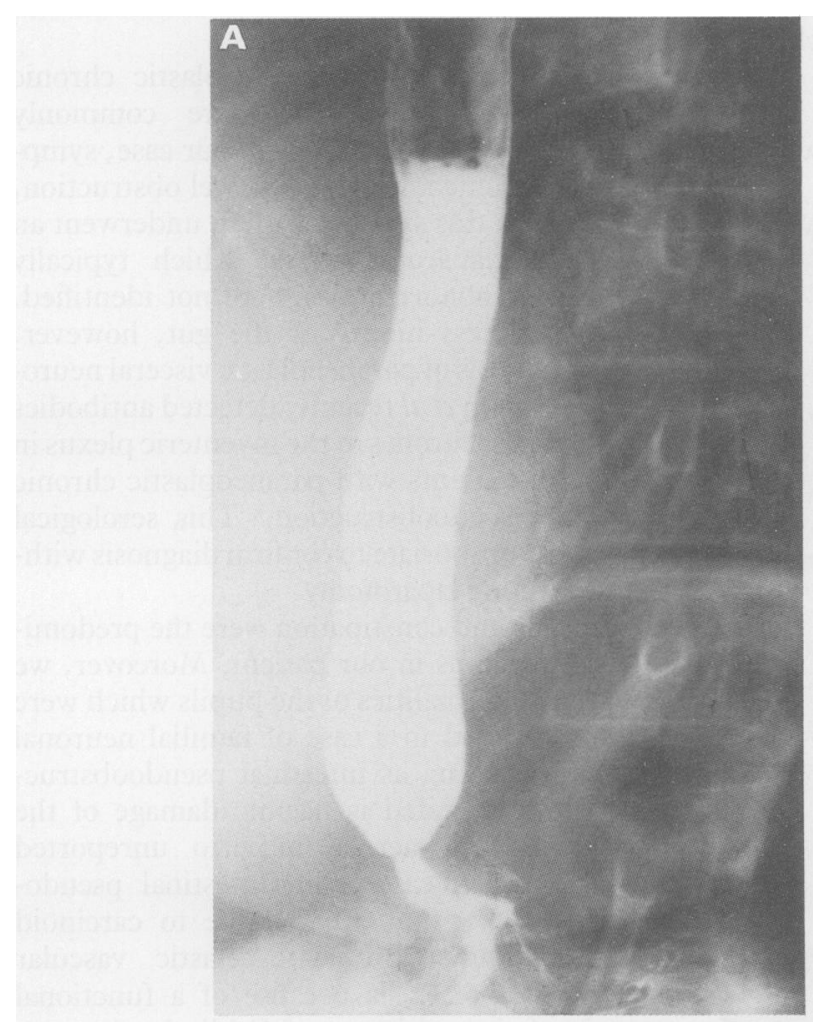

B
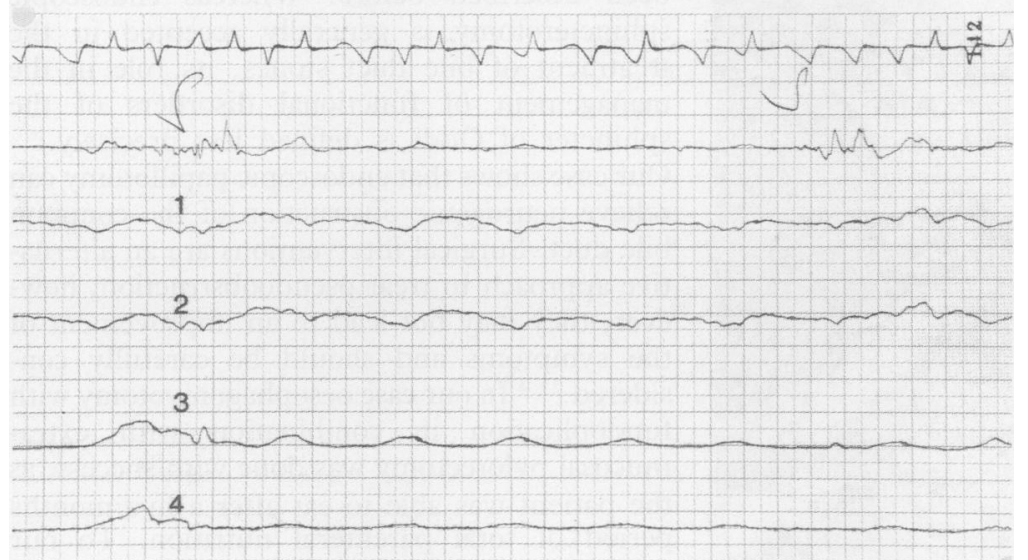

Figure 1: (A) Barium swallow taken four weeks after onset of dysphagia revealing a considerable stenosis of the distal oesophagus. (B) Manometry documenting lack of propulsive movement and diffuse oesophageal spasms consistent with achalasia. $(S=$ swallow, $1-4=$ marking of the channels. the colon with a lack of haustration. Twenty three days after an upper gastrointestinal series there was still barium in the right colon. But neither gastrografin enema nor repeated colonoscopy revealed any mechanical obstruction.

No improvement of the gastrointestinal motility was achieved with metoclopramide or cholinergic agents, also cisapride had no therapeutic effect. Therefore, a venous port a-cath system was implanted and the patient received complete parenteral nutrition over a period of five months. Neither prednisone $(2 \mathrm{mg} / \mathrm{kg}$ body weight) nor administration of the somatostatin analogue SMS 201-995 led to any symptomatic relief.

In March 1989, painless obstructive jaundice with dark coloured urine developed. Total bilirubin was $88.0 \mu \mathrm{mol} / \mathrm{l}$ (normal range 3.4 $17 \cdot 1 \mu \mathrm{mol} / \mathrm{l}$ ), alkaline phosphatase $18 \cdot 2 \mu \mathrm{mol} \times$ $\mathrm{sec}^{-1} / 1$ (normal range $0.6-2 \cdot 2 \mu \mathrm{mol} \times \mathrm{sec}^{-1} / 1$ ), gamma glutamyl transpeptidase $17 \cdot 1 \mu \mathrm{mol} \times$ $\mathrm{sec}^{-1} / 1$ (normal range $0 \cdot 1-0.3 \mu \mathrm{mol} \times \mathrm{sec}^{-1} / 1$ ), SGPT $2200 \mathrm{nmol} \times \mathrm{sec}^{-1} / 1$ (normal range 150 $\left.300 \mathrm{nmol} \times \mathrm{sec}^{-1} / 1\right)$, SGOT $1283 \mathrm{nmol} \times \mathrm{sec}^{-1} / 1$ (normal range $100-250 \mathrm{nmol} \times \mathrm{sec}^{-1} / 1$ ). Ultrasound examination revealed an enlarged gall bladder filled with sludge but no concrements; the common bile duct was dilated $(20 \mathrm{~mm})$ and the intrahepatic ducts were visible. Endoscopic retrograde cholangiopancreatographic examination did not detect any concrements, a pancreas or bile duct tumour or any compression of the common bile duct. A functional stenosis of the sphincter of Oddi was diagnosed and treated by endoscopic papillotomy. Within 10 days the laboratory values returned to normal.

In April 1989, endoscopic dilatation of the lower oesophageal sphincter was tried without success. Another operation was undertaken because of persistent severe dysphagia and refractory vomiting. Oesophagomyotomy with fundoplication in combination with extramucosal pylorectomy and resection of the hepatic metastases were performed. The hepatic metastases were confirmed histologically. The postoperative course was complicated by a subhepatic abscess which was treated by percutaneous draining and antibiotic therapy. Three weeks after surgery, the patient began to eat. Parenteral nutrition was discontinued six weeks postoperatively and the patient subsequently maintained her weight $(50 \mathrm{~kg})$. Abdominal pain and severe obstipation, however, persisted and repeated anal sphincter dilatation was necessary.

In August 1989, the patient developed intestinal infarction with gangrene of the jejunum. After small bowel resection she died of refractory septic shock 10 months after onset of gastrointestinal symptoms.

Postmortem examination revealed evidence of a metastasised carcinoid being composed of rather uniform epithelial cells in cords and nests (Fig 2a). Tumour masses were present in the residual right major bronchus, in paratracheal but also in iliac and mesenteric lymph nodes and both ovaries $(5.5 \mathrm{~cm})$. Haematogenous spread was also localised in the liver $(1.5 \mathrm{~cm})$ and as a solitary epidural mass in the right parietooccipital region $(7 \mathrm{~cm})$.

Like the surgical specimen of the small 
intestine the residual small and large bowel and also the stomach showed massive ischaemic tissue damage with transmural necrosis and inflammatory reaction. There was only minimal general arteriosclerosis. Especially in the mesenteric arteries no elastic vascular sclerosis could be visualised.

Most impressive was a loss of ganglion cells in the myenteric plexus, accompanied by a loose cellular infiltrate of lymphocytes and plasma cells with additional glial cell proliferation (Fig 2b); no morphological abnormalities of smooth muscle layers were identified. In control specimens of autopsy bowel and surgically removed ischaemic intestine no such neurone loss could be demonstrated.

\section{Discussion}

Small cell carcinomas of the lung and less frequently carcinoid tumours have been recognised to cause various neurological disorders. ${ }^{4-10}$ Whereas in 11 cases of paraneoplastic chronic intestinal pseudoobstruction small cell carcinoma of the lung was the underlying malignancy, ${ }^{23}$ only one case associated with a

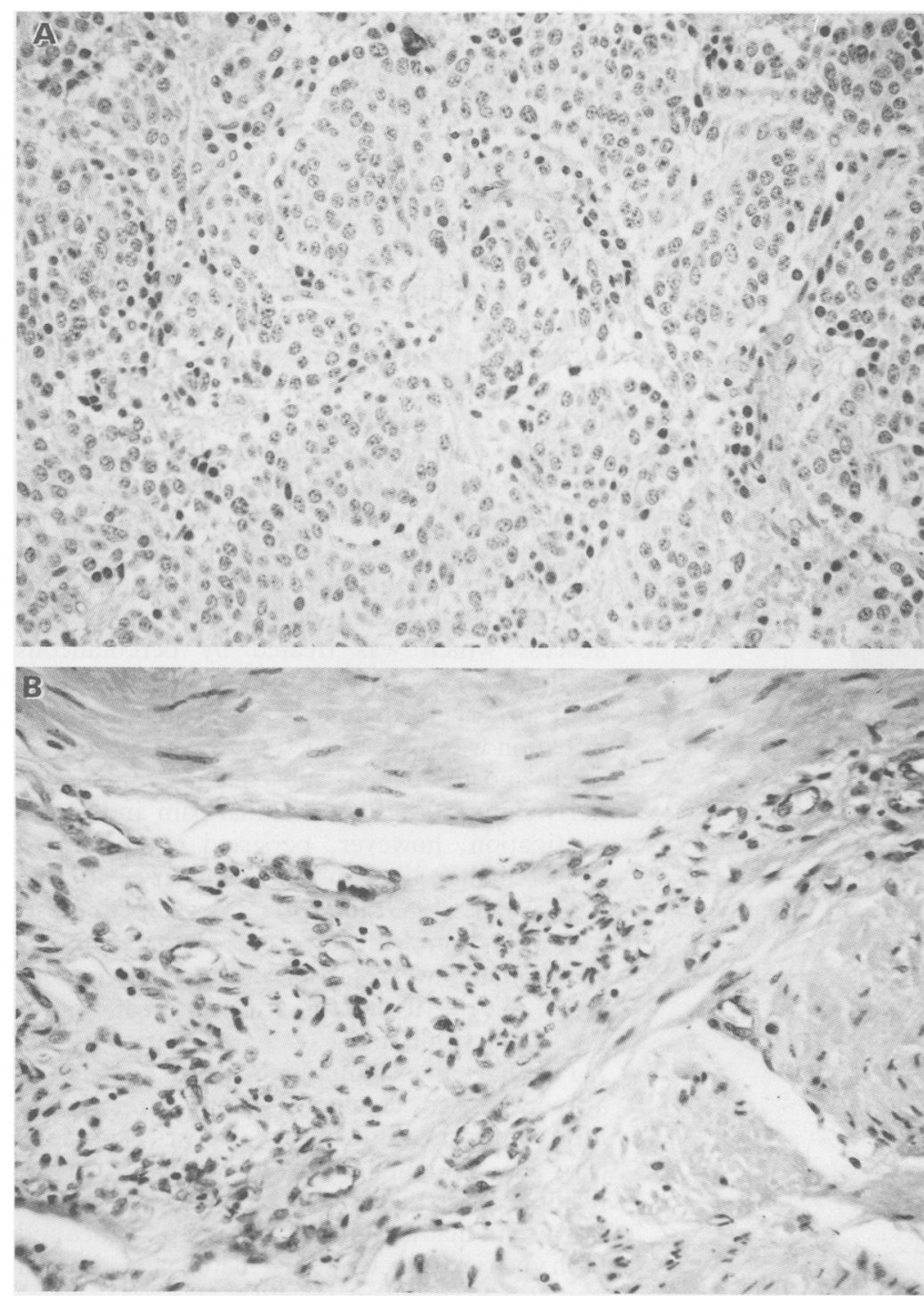

Figure 2: (A) Morphology of the carcinoid tumour (liver metastasis) with monomorphous tumour cells arranged in cell nests. $H \mathcal{E} E$. (B) Plexus myentericus of musculus sphincter pylori being devoid of ganglion cells and enriched with glial cell proliferation as well as sparse lympho plasmacellular inflammatory infiltrate. $H \mathcal{E} E$. bronchial carcinoid has been reported hitherto. Common histologic, electron microscopic and tissue culture characteristics" as well as similar immunophenotypes ${ }^{12}$ of small cell lung carcinoma and bronchial carcinoid could explain the fact that paraneoplastic visceral neuropathy is found in both malignancies.

Oesophageal dysmotility (diffuse oesophageal spasms or complete achalasia), gastroparesis, intestinal pseudoobstruction and constipation were described to be major symptoms of paraneoplastic visceral neuropathy. ${ }^{2313}$ In addition, neurogenic bladder, peripheral neuropathy, autonomic neuropathy or central nervous system dysfunction were encountered in some patients. $^{23}$ Whereas in the above mentioned reports gastrointestinal symptoms preceded the discovery of the lung tumour by one to 26 months in 11 of 12 cases, in our patient gastrointestinal motor disturbance began 54 months after diagnosis of the bronchial carcinoid and was accompanied by the detection of distant metastases.

Initial symptoms of paraneoplastic chronic intestinal pseudoobstruction are commonly uncharacteristic. Because, as in our case, symptoms may mimic mechanical bowel obstruction, patients with this syndrome often underwent an exploratory laparotomy ${ }^{313}$ at which typically macroscopic abnormalities were not identified. A full thickness biopsy of the gut, however allows diagnosis of paraneoplastic visceral neuropathy. ${ }^{3}$ Lennon et al recently detected antibodies reactive with neurones of the myenteric plexus in the sera of patients with paraneoplastic chronic intestinal pseudoobstruction. ${ }^{3}$ This serological test seems appropriate to confirm diagnosis without performing laparotomy.

Achalasia and constipation were the predominating symptoms in our patient. Moreover, we observed abnormalities of the pupils which were earlier described in a case of familial neuronal disease presenting as intestinal pseudoobstruction. ${ }^{14}$ The extended ischaemic damage of the gastrointestinal tract, a hitherto unreported phenomenon in cases with intestinal pseudoobstruction was not attributable to carcinoid associated angiopathy with elastic vascular sclerosis. ${ }^{15}$ Cholestasis because of a functional stenosis of the sphincter of Oddi also has not been described before. Whereas endoscopic sphincterotomy is generally accepted in the treatment of bile duct stones, its role in the management of functional disorders of the sphincter of Oddi is defined less precisely..$^{16}$ Our case shows that endoscopic papillotomy can relieve neurogenic obstruction of the common bile duct. Surgical interventions are an alternative approach to treat pseudoobstruction; however, they may not lead to an improvement of the symptoms and should be carefully considered. ${ }^{2318}$ In our case oesophagomyotomy with fundoplication in combination with extramucosal pylorectomy was done with success, as the patient was able to eat after a five months period of total parenteral nutrition. To our knowledge this procedure has not been described by others.

Data in the literature ${ }^{3}$ as well as laboratory findings in our patient including antibodies 
to Sm-antigen, positive rheumatoid factor, increased gamma globulin fraction in serum electrophoresis and circulating immune complexes suggest an autoimmune pathogenesis of paraneoplastic visceral neuropathy. This pathogenesis may be related to that involved in lupus erythematosus as recently discussed by Thirkill et al for cancer associated retinopathy. ${ }^{19}$ Cytolysis of tumour cells could lead to the release of nuclear antigens which induce the production of autoantibodies. As similar antigens are located on small cell lung carcinoma cells and nervous system cells, ${ }^{2021}$ the immune response to tumour antigens may cross react with neuronal cells. The resulting antigen antibody complex may mediate neuronal injury. An alternative hypothesis is that antinuclear antibodies do not play a pathogenetic role, but are generated by an autoimmune process. Assuming an autoimmune pathogenesis of paraneoplastic neuropathies treatments with steroids, immunosuppressive drugs or even plasmapheresis were performed, but without success. ${ }^{1922}$ The irreversible loss of neurones in the myenteric plexus could have been the reason for the failure of steroid treatment in our case.

We thank Dr H Fürst for permission to use the oesophagus manometry.

1 Colemont LJ, Camilleri M. Chronic intestinal pseudoobstruction: diagnosis and treatment. Mayo Clin Proc 1989; 64: $60-70$.

2 Chinn JS, Schuffler MD. Paraneoplastic visceral neuropathy as a cause of severe gastrointestinal motor dysfunction. as a cause of severe gastrointestinal
Gastroenterology 1988; $95: 1279-86$.

3 Lennon VA, Sas DF, Busk MF, Scheithauer B, Malagelad $\mathrm{JR}$, Camilleri M, et al. Enteritic neuronal auto-antibodies in pseudo-obstruction with small-cell lung carcinoma. Gastroenterology 1991; 100: 137-42.

4 Green D, Joynt RJ, Van Allen MW. Neuromyopathy associated with a malignant carcinoid tumor. Arch Intern Med 1964; 114: 494-6.
5 Berry EM, Maunder C, Wilson M. Carcinoid myopathy and treatment with cyproheptadine (periactin). Gut 1974; 15 : 34-8.

6 Wroe SJ, Ardron M, Bowden AN. Myasthenia gravis associated with a hormone producing malignant carcinoid tumo [Letter]. F Neurol Neurosurg Psychiatry 1985; 48: 719-20.

7 Sipilä R, Leinonen H, Juntunen J. Paraneoplastic polyneuropathy associated with a carcinoid tumor of the cecum. Acta Med Scand 1982; 212: 183-4.

8 Carr-Locke DL. Autonomic neuropathy and inappropriate secretion of antidiuretic hormone. Occurence in a patien with bronchogenic carcinoma. FAMA 1979; 241: 2298.

9 Zweifel TJ, Albers JW. Multiple neurologic paraneoplastic syndromes. Arch Neurol 1980; 37: 315-6.

10 Dropcho EJ, Stanton C, Oh SJ. Neuronal antinuclear antibodies in a patient with Lambert-Eaton myasthenic syndrome and small-cell lung carcinoma. Neurology 1989; 39 . 249-51.

11 Fisher ER, Palekar A, Paulson JD. Comparative histopathologic, histochemical, electron microscopic and tissue culture studies of bronchial carcinoids and oat cell carcinomas of lung. Am F Clin Pathol 1978; 69: 165-72.

12 Doria MI, Montag AG, Franklin WA. Immunophenotype of small cell lung carcinoma. Expression of NKH-l and transferrin receptor and absence of most myeloid antigens. Cancer 1988; 62: 1939-45.

13 Schuffler MD, Baird W, Fleming R, Bell CE, Bouldin TW Malagelada JR, et al. Intestinal pseudo-obstruction as the presenting manifestation of small-cell carcinoma of the lung. Ann Intern Med 1983; 98: 129-34.

14 Schuffler MD, Bird TD, Sumi SM, Cood A. A familia neuronal disease presenting as intestinal pseudoobstruction. Gastroenterology 1978; 75: 889-98.

15 Harvey JN, Denyer ME, DaCosta P. Intestinal infarction caused by carcinoid associated elastic vascular sclerosis: caused by carcinoid associated elastic vascular sclerosis: early presentation

16 Steinberg WM. Sphincter of Oddi dysfunction: a clinical controversy. Gastroenterology 1988; 95: 1409-15.

17 Krims PE, Cotton PB. Papillotomy and functional disorders of the sphincter of Oddi. Endoscopy 1988; 20: 203-6.

18 Schuffler MD, Deitch EA. Chronic idiopathic intestinal pseudo-obstruction. A surgical approach. Ann Surg 1980, 192: 752-61

19 Thirkill CE, FitzGerald P, Sergott RC, Roth AM, Tyler NK, Keltner JL. Cancer-associated retinopathy (CAR syndrome) with antibodies reacting with retinal, optic nerve and cancer cells. NEngl f Med 1989; 321: 1589-94.

20 Bell CE, Seetharam S, McDaniel RC. Entodermally-derived and neural crest-derived differentiation antigens expressed by a human lung tumor. F Immunol 1976; 116: 1236-43.

21 Bell CE, Seetharam S. Expression of entodermally derived and neural crest-derived differentiation antigens by human lung and colon tumors. Cancer 1979; 44: 13-8

22 Anderson NE, Rosenblum MK, Graus F, Wiley RG, Posner JB. Autoantibodies in paraneoplastic syndromes associated with small cell lung cancer. Neurology 1988; 38: 1391-8. 